\title{
An Incidental Detection of Nutcracker Phenomenon in an Adolescent with Transient High Blood Pressure: A Case Report
}

\author{
Min Cai ${ }^{1}$, Haibin Chen², Haixiong Wang ${ }^{3}$, Hong Zhang ${ }^{3}$, Guisheng Feng1, Xiaohong Zhang4, \\ Jian Chen 4 , Jiyun $\mathrm{Du}^{3}$
}

${ }^{1}$ Department of Nuclear Medicine, Shanxi Provincial People's Hospital, Taiyuan, China

${ }^{2}$ Department of Anorectal Surgery, Shanxi Hospital of Integrated Traditional and Western Medicine, Taiyuan, China

${ }^{3}$ Department of Cardiology, Shanxi Provincial People’s Hospital, Taiyuan, China

${ }^{4}$ Department of Ultrasound, Shanxi Provincial People's Hospital, Taiyuan, China

Email: c.m1113@163.com

How to cite this paper: Cai, M., Chen, H.B., Wang, H.X., Zhang, H., Feng, G.S., Zhang, X.H., Chen, J. and Du, J.Y. (2016) An Incidental Detection of Nutcracker Phenomenon in an Adolescent with Transient High Blood Pressure: A Case Report. Case Reports in Clinical Medicine, 5, 431436.

http://dx.doi.org/10.4236/crcm.2016.511060

Received: October 19, 2016

Accepted: November 1, 2016

Published: November 4, 2016

Copyright $\odot 2016$ by authors and Scientific Research Publishing Inc. This work is licensed under the Creative Commons Attribution International License (CC BY 4.0).

http://creativecommons.org/licenses/by/4.0/

\section{(c) (i) Open Access}

\begin{abstract}
Nutcracker phenomenon (NCP) is caused by a compression of left renal vein between aorta and superior mesenteric artery. The traditional clinical manifestations of nutcracker syndrome is usually accompanied with abdominal pain, hematuria, orthostatic proteinuria, and varicocele formation, however, hypertension is rarely reported as main clinical feature. We describe a male adolescent with manifestation of hypertension who was identified as NCP. Renal ultrasound and computed tomography angiography have provided evidences of left renal vein dilatation, probably due to the compression through the decreased angle between aorta and superior mesenteric artery. There were no other signs for secondary hypertension for the blood levels of renin and aldosterone being between normal limits and urinalysis being negative of hematuria and proteinuria. This patient was conservatively observed without any anti-hypertensive drugs and was asked for appropriately putting on weight. Three months later, the hypertension symptom was alleviated. In conclusion, although there were no established direct pathogenetic links between hypertension and NCP, no other definite etiology was shown to be the cause of this main manifestation. Thus we speculate that the NCP might be the main cause of hypertension in this patient.
\end{abstract}

\section{Keywords}

Secondary Hypertension, Adolescent, Left Renal Vein, Nutcracker Phenomenon 


\section{Introduction}

Nutcracker phenomenon (NCP), also known as left renal vein entrapment, is characterized by impeded outflow from the left renal vein (LRV) into the inferior vena cava due to extrinsic LRV compression, often accompanied by demonstrable lateral (hilar) dilatation and medial (mesoaortic) narrowing. The nutcracker syndrome (NCS) is the clinical equivalent of NCP characterized by a complex of symptoms with substantial variations, which is also called "renal vein entrapment syndrome" [1]. These anatomical findings were first described by Schepper in 1972 [2], who first proposed the term "nutcracker", and first elaborated the pathophysiologic process of renal hemorrhage caused by this phenomenon. Most typical nutcracker morphologic features imply compression of the LRV between the aorta and the superior mesenteric artery (SMA), known as anterior nutcracker. Less often, the third portion of the duodenum courses in front of the LRV between the aorta and the SMA. The retroaortic or circumaortic renal vein may be compressed between the aorta and the vertebral body, which is called posterior nutcracker. NCP is a rare clinical condition that more occurs relatively in adolescents or young adults and previously healthy patients. It is characterized usually by mild hematuria, orthostatic proteinuria, mild anemia and chronic fatigue, left flank pain, left-sided varicocele in males and pelvic congestion in females [3]. In this article, we describe a young male with hypertension caused by NCP, which probably is the rarest cause of hypertension.

\section{Case Report}

A 17-year-old male with detection of high blood pressure $(135 / 110 \mathrm{mmHg})$ in health examination for a month was admitted for further evaluation. He has no history of surgery, trauma and infection, and his family history was negative for hypertension or renal diseases. The patient was primarily treated with hypertension patient's routine nursing, as well as low salt and low fat diet.

The patient has a lanky shape and body mass index (BMI) is 18.6, but physical examination was unremarkable. Serum potassium, sodium and chlorine were all in normal range. Serum tests for rennin, angiotensin I, angiotensin II and aldosterone were also normal separately in orthostatic and decubitus position. The 24 hour cortisol diurnal testing result showed: cortisol in 8 o'clock, 16 o'clock were high (separately 540.2 $\mu \mathrm{g} / \mathrm{dl}$ and $317.2 \mu \mathrm{g} / \mathrm{dl}$, normal $50-280 \mu \mathrm{g} / \mathrm{dl}$ ), and in 0 o'clock it was within normal limits. Adrenocorticotropic hormone was normal. Immunological investigation including antinuclear antibodies, antineutrophil cytoplasmic antibodies, and anti-glomerularbasement membrane antibody were all within normal limits. Urinary albumin was above normal $(20.8 \mu \mathrm{g} / \mathrm{ml}$, normal $1.2-14.8 \mu \mathrm{g} / \mathrm{ml})$, and albumin in 24 hour urine collections was negative $(0.06 \mathrm{~g} / 24 \mathrm{~h}$, normal $<0.25 \mathrm{~g} / 24 \mathrm{~h})$. Urinalysis did not reveal any other abnormalities including hematuria.

After admission, the patient had undergone cardiovascular examination including a chest X-ray and echocardiography that were normal. As there was no other signs indicative of secondary hypertension, a renal ultrasound with a Doppler renal arteries scan 
and a computed tomography angiography (CTA) were performed. Supine admission measurement in renal ultrasound examination showed an obvious stenosis and dilatation of the LRV without any signs of varices. The LRV was compressed in the angle between SMA and abdominal aorta, in which the proximal venous dilation was noted (antero-posterior diameter $0.92 \mathrm{~cm}$ in the hilar portion, $0.17 \mathrm{~cm}$ in the narrow portion, ratio 5.4. see Figure 1(a)). Doppler flow peak velocity was $252 \mathrm{~cm} / \mathrm{s}$ in the narrow portion. CTA had revealed signs of LRV stenosis and dilation (see Figure 2), angle between aorta and SMA was about $18^{\circ}$. The renal ultrasound and CTA results indicated this manifestation as NCP. Compared to invasive procedure left renal retrograde venography, non invasive examinations such as Doppler ultrasonography and CTA remain the main procedures to final diagnosis of NCP [4] [5] [6]. Our patient was conservatively observed without any anti-hypertensive drugs and be asked for putting on weight appropriately. He was followed up 3 months later and renal ultrasound revealed that the LRV compression was relieved (hilar portion $1.10 \mathrm{~cm}$, narrow portion $0.20 \mathrm{~cm}$, ratio 5.5; narrow portion flow peak velocity was $114 \mathrm{~cm} / \mathrm{s}$. see Figure 1(b)).

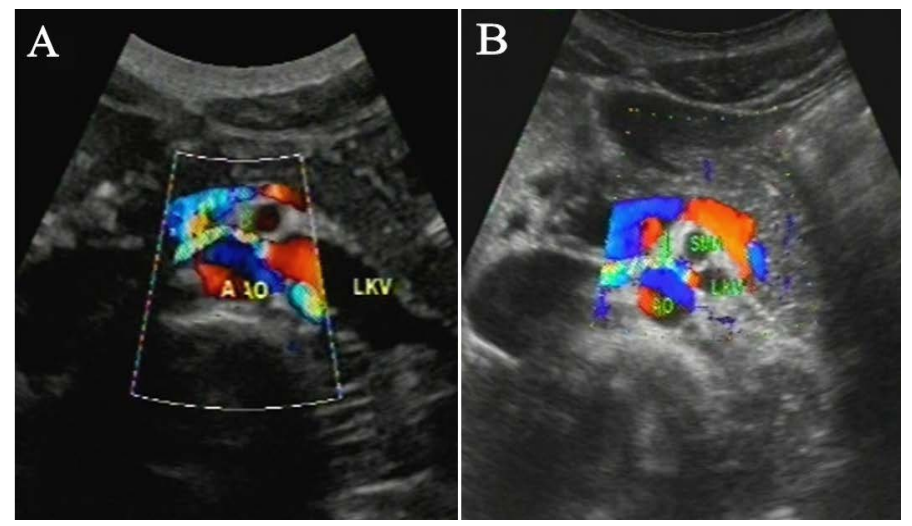

Figure 1. Renal ultrasound in transverse view. (A) Compressed LRV between the aorta (AO) and superior mesenteric artery (SMA). The diameter was $0.17 \mathrm{~cm}$, and the Doppler flow peak velocity was $252 \mathrm{~cm} / \mathrm{s}$ in the narrow portion. (B) Three months later, the diameter of LRV was $0.20 \mathrm{~cm}$ and the Doppler flow peak velocity was $114 \mathrm{~cm} / \mathrm{s}$ in the narrow portion.
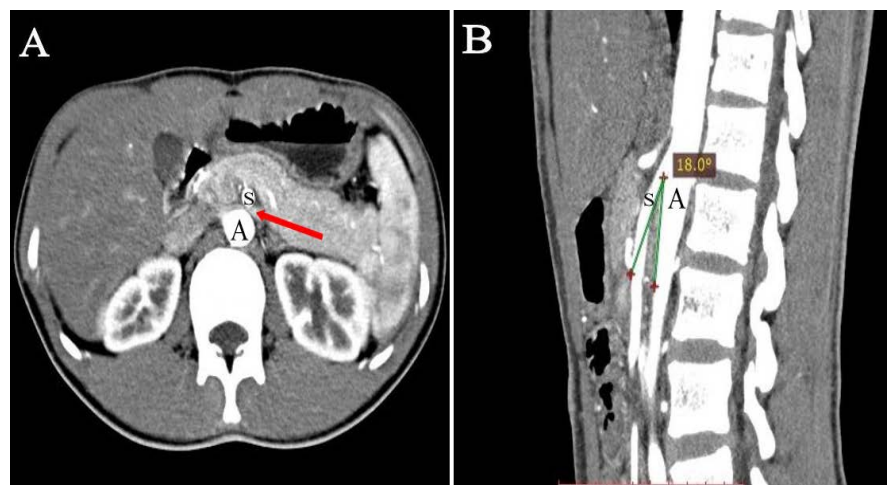

Figure 2. CTA shows the relationship of SMA (S), aorta (A) and LRV (arrow) in coronal (A) and sagittal (B) planes in this patient. (A) LRV is compressed when it crosses between aorta and SMA. (B) SMA compresses LRV with initial steep caudal descent with aorta at the angle of $18^{\circ}$. 


\section{Discussion}

Most symptomatic patients of NCP are usually adolescents or young adults [1]. In puberty, some adolescents, especially those with slender shapes, grow rapidly with vertebral excessive stretching and abdominal viscera prolapsing, which pull SMA to a decreased angle in upright position. Lower BMI correlates positively with the incidence of NCP [7]. However, in some adults, the reduction of adipose tissue at the initial part of SMA, as well as the enlargement of lymph nodes or tumors, could also result in the LRV compression. Although some patients have severe and persistent symptoms, commonly including hematuria, left flank pain or gonadal vein syndrome, varicocele, orthostatic proteinuria, and orthostatic intolerance [8] [9], many patients, especially in children, are asymptomatic. However, hypertension is not included in the traditional clinical manifestations of the syndrome [1].

Hosotani et al. [10] reported a case of NCP and hypertension with increased plasma renin and aldosterone levels in the peripheral blood in a young Japanese woman. The patient was found severe LRV stenosis and ovarian veins dilated via selective renal venography. The authors also reported increased renin levels in the LRV and an increased renocaval pressure gradient that was indicative of NCP. The patient became normotensive and renin levels normalized after endovascular stent placement in the affected renal vein. It indicated that the high renin activity was corrected with NCP. Some investigators have suggested that elevated renal pressures (venous and interstitial) reduce glomerular filtration, affect intrarenal blood flow, and stimulate release of renin [11]. With reduced glomerular filtration, there is reduction of sodium delivery to the macula densa, which triggers renin secretion from the juxtaglomerular cells. Therefore, LRV hypertension may have caused renin secretion in that patient. In our case, the patient's plasma rennin, angiotensin and aldosterone activity were all within the normal limits, although only the cortisol value were high beyond the normal range at 8 o'clock and 16 o'clock. It is unclear that the increased cortisol was associated with hypertension, because the serum potassium and sodium were both normal, which was not compatible with symptoms of Cushing syndrome. As far as our patient concerned, we were not able to identify any cause that might be related with secondary hypertension. The accidental finding of LRV compression led us to investigate a possible relation with hypertension. In 2012, Mazarakis et al. [3] reported a 20-year-old male with hypertension as a manifestation of NCP and there were no other signs for secondary hypertension. The blood levels of rennin, aldosterone, and renocaval pressure gradient were between normal limits. As there were coexisting anatomical and clinical findings, NCP might have been the single cause of hypertension. In this respect, our patient had the same characteristics as Mazarakis's case. Considering the NCP patients may have diversified clinical manifestations, we speculate in some patients with NCP, hypertension could be the single manifestation.

The treatment options of NCP range from observation to surgical operation or vascular intervention, depending on the severity of symptoms [1]. For those younger than 18 years old, the best option is conservative approach with observation for at least 2 
years because with teenagers' growth, the angle of SMA and aorta may increase or the adipose tissue may fill with the initial part of SMA and there could establish collateral circulation, which relieves the LRV pressure, and as many as 75\% of young NCP patients could outgrown their symptoms [12]. For the mild cases such as hematuria, conservative treatment is usually recommended. For more severe symptoms, the surgical operation or vascular intervention aims to decrease LRV hypertension and relieve pelvic congestion [13] [14] [15]. Our patient was conservatively observed without any anti-hypertensive drugs. Three months later, the patient's weight gained 2 - 3 kilograms and the blood pressure was reduced to $120 / 90 \mathrm{mmHg}$.

\section{Conclusion}

In conclusion, we report a hypertensive adolescent of radiological evidence of NCP. Although there were no established direct pathogenetic links between hypertension and NCP, no other definite aetiological agent was shown to be the cause of this main clinical manifestation. In some patients with NCP, hypertension might be the single manifestation.

\section{Acknowledgements}

This study is supported by the Natural Science Foundation of China (81401449) and Scientific Research Subject of Health and Family Planning Commission of Shanxi Province (2014110).

\section{Conflicts of Interest}

The authors report no specific funding in relation to this research and no conflicts of interest to disclose.

\section{References}

[1] Kurklinsky, A.K. and Rooke, T.W. (2010) Nutcracker Phenomenon and Nutcracker Syndrome. Mayo Clinic Proceedings. Mayo Clinic, 85, 552-559.

http://dx.doi.org/10.4065/mcp.2009.0586

[2] de Schepper, A. (1972) "Nutcracker" Phenomenon of the Renal Vein and Venous Pathology of the Left Kidney. Journal Belge de Radiologie, 55, 507-511.

[3] Mazarakis, A., Almpanis, G., Tragotsalou, N., Karnabatidis, D. and Fourtounas, C. (2012) Is Hypertension a Manifestation of the Nutcracker Phenomenon/Syndrome? Case Report and Brief Review of the Literature. Hippokratia, 16, 187-189.

[4] Shokeir, A.A., el-Diasty, T.A. and Ghoneim, M.A. (1994) The Nutcracker Syndrome: New Methods of Diagnosis and Treatment. British Journal of Urology, 74, 139-143. http://dx.doi.org/10.1111/j.1464-410X.1994.tb16574.x

[5] Kim, S.H., Cho, S.W., Kim, H.D., Chung, J.W., Park, J.H. and Han, M.C. (1996) Nutcracker Syndrome: Diagnosis with Doppler US. Radiology, 198, 93-97.

http://dx.doi.org/10.1148/radiology.198.1.8539413

[6] Russo, D., Minutolo, R., Iaccarino, V., Andreucci, M., Capuano, A. and Savino, F.A. (1998) Gross Hematuria of Uncommon Origin: The Nutcracker Syndrome. American Journal of 
Kidney Diseases, 32, e3.1-e3.4. http://dx.doi.org/10.1053/ajkd.1998.v32.pm10074588

[7] Shaper, K.R., Jackson, J.E. and Williams, G. (1994) The Nutcracker Syndrome: An Uncommon Cause of Haematuria. British Journal of Urology, 74, 144-146.

http://dx.doi.org/10.1111/j.1464-410X.1994.tb16575.x

[8] Hohenfellner, M., Steinbach, F., Schultz-Lampel, D., Schantzen, W., Walter, K., Cramer, B.M., et al. (1991) The Nutcracker Syndrome: New Aspects of Pathophysiology, Diagnosis and Treatment. The Journal of Urology, 146, 685-688.

[9] Ahmed, K., Sampath, R. and Khan, M.S. (2006) Current Trends in the Diagnosis and Management of Renal Nutcracker Syndrome: A Review. European Journal of Vascular \& Endovascular Surgery, 31, 410-416. http://dx.doi.org/10.1016/j.ejvs.2005.05.045

[10] Hosotani, Y., Kiyomoto, H., Fujioka, H., Takahashi, N. and Kohno, M. (2003) The Nutcracker Phenomenon Accompanied by Renin-Dependent Hypertension. The American Journal of Medicine, 114, 617-618. http://dx.doi.org/10.1016/S0002-9343(03)00091-3

[11] Doty, J.M., Saggi, B.H., Sugerman, H.J., Blocher, C.R., Pin, R., Fakhry, I., et al. (1999) Effect of Increased Renal Venous Pressure on Renal Function. The Journal of Trauma, 47, 1000-1003. http://dx.doi.org/10.1097/00005373-199912000-00002

[12] Shin, J.I., Park, J.M., Lee, S.M., Shin, Y.H., Kim, J.H., Lee, J.S., et al. (2005) Factors Affecting Spontaneous Resolution of Hematuria in Childhood Nutcracker Syndrome. Pediatric Nephrology (Berlin, Germany), 20, 609-613. http://dx.doi.org/10.1007/s00467-004-1799-z

[13] Chuang, C.K., Chu, S.H. and Lai, P.C. (1997) The Nutcracker Syndrome Managed by Autotransplantation. The Journal of Urology, 157, 1833-1834.

http://dx.doi.org/10.1016/S0022-5347(01)64872-9

[14] Segawa, N., Azuma, H., Iwamoto, Y., Sakamoto, T., Suzuki, T., Ueda, H., et al. (1999) Expandable Metallic Stent Placement for Nutcracker Phenomenon. Urology, 53, 631-633. http://dx.doi.org/10.1016/S0090-4295(98)00355-0

[15] Park, Y.B., Lim, S.H., Ahn, J.H., Kang, E., Myung, S.C., Shim, H.J., et al. (2000) Nutcracker Syndrome: Intravascular Stenting Approach. Nephrology Dialysis Transplantation, 15, 99101. http://dx.doi.org/10.1093/ndt/15.1.99

\section{Submit or recommend next manuscript to SCIRP and we will provide best service for you:}

Accepting pre-submission inquiries through Email, Facebook, LinkedIn, Twitter, etc.

A wide selection of journals (inclusive of 9 subjects, more than 200 journals)

Providing 24-hour high-quality service

User-friendly online submission system

Fair and swift peer-review system

Efficient typesetting and proofreading procedure

Display of the result of downloads and visits, as well as the number of cited articles

Maximum dissemination of your research work

Submit your manuscript at: http://papersubmission.scirp.org/

Or contact crcm@scirp.org 